\title{
Fatores Ambientais na Distribuição de Populações de Brachiaria subquadripara PREsentes NO RESERVATóRIO DE BARRA BONITA-SP ${ }^{1}$
}

\author{
Environmental Factors in the Distribution of Brachiaria subquadripara Populations in Barra \\ Bonita Reservoir-SP, Brazil
}

DOMINGOS, V.D. ${ }^{2}$, MARTINS, D. ${ }^{3}$, COSTA, N.V. ${ }^{4}$ e MARCHI, S.R. ${ }^{5}$

\begin{abstract}
RESUMO - Este estudo teve como objetivos monitorar a distribuição de populações de Brachiaria subquadripara e caracterizar seu ambiente de ocorrência em duas épocas (seca e águas). As coletas foram realizadas em julho de 2004 e janeiro de 2005 em pontos previamente selecionados e georreferenciados, os quais se constituíram de 13 pontos no reservatório Barra Bonita (sete pontos no braço do rio Piracicaba e seis no braço do rio Tietê). Foram realizadas coletas de solo nas margens dos rios, sedimento, água e plantas. A distribuição em relação à área de infestação das populações de $B$. subquadripara observada na estação chuvosa foi influenciada pela variação sazonal, a qual ocorreu de forma heterogênea em relação à densidade populacional. O rio Tietê foi considerado um ambiente mais eutrófico do que o rio Piracicaba tanto em relação ao solo quanto em relação à coluna d'água. As amostras de água coletadas no rio Tietê apresentaram valores médios de pH na estação seca de 7,02 a 7,82 , e na estação das águas registrou-se maior amplitude de variação $(6,80$ a 8,0). A maioria dos pontos amostrados apresentou altos teores de matéria orgânica no sedimento, sendo observados teores menores que $1,3 \%$ em dois pontos de coleta na época da seca e em cinco pontos na época das águas.
\end{abstract}

Palavras-chave: braquiária, habitat, levantamento, planta aquática, planta daninha.

\begin{abstract}
The objectives of this work were to study the distribution of Brachiaria subquadripara populations and to characterize their environment of occurrence in two seasons (dry and rainy). Surveys were carried out in July, 2004 and January, 2005, in 13 previously selected and georeferred sites in the Barra Bonita reservoir (seven in the Piracicaba River effluent and six in the Tietê River effluent). Soil, sediment, water and plant samples were collected on the river banks at these sites for analysis. Distribution in relation to infestation area of $\boldsymbol{B}$. subquadripara populations was influenced by the seasonal variation distribution of the populations, which occurred heterogeneously in relation to population density. Tietê River was considered a more eutrophic environment than the Piracicaba river, regarding both soil and water column. The water samples collected in Tietê River showed mean $\mathrm{pH}$ values in the dry season from 7.02 to 7.82, and a wider variation (6.80 to 8.0) in the rainy season. Most of the sites sampled showed high concentrations of organic matter in the sediment, with concentrations lower than 1.3\% being observed in two sites in the dry season (winter) and in five sites in the rainy season (summer).
\end{abstract}

Keywords: Brachiaria, habitat, survey, aquatic plant, weed.

1 Recebido para publicação em 14.1.2011 e na forma revisada em 18.2.12011.

Parte da tese de doutorado do primeiro autor apresentada à FCA/UNESP;

2 Professora, Dra., IFECT-TO/Palmas, <vanessadd@ifto.edu.br>; ${ }^{3}$ Professor Livre Docente, Dep. de Produção Vegetal, FCA/UNESP, Caixa Postal 237, 18603-970 Botucatu-SP, Brasil, <dmartins@fca.unesp.br>; ${ }^{4}$ Professor Adjunto, UNIOESTE, Marechal Cândido Rondon-PR, <neumarciovc@hotmail.com>; ${ }^{5}$ Professor Adjunto, ICET/UFMT, Barra do Garça-MT, $<$ sidneimarchi.ufmt@gmail.com>. 


\section{INTRODUÇÃO}

O estado trófico de rios e lagos tem sido alterado principalmente pelo influxo de nutrientes provenientes do despejo de esgotos urbanos e industriais. A eutrofização, inicialmente, pode ocorrer de forma natural em ecossistemas aquáticos. No entanto, também pode ser acelerada pelo aumento crescente da concentração de nutrientes devido também ao carreamento de solo do ecossistema agrícola, que apresenta como consequência aumento na produtividade biológica, cujos efeitos podem ser mais expressivos na vegetação aquática.

Nessas condições ambientais ocorre o crescimento excessivo de plantas aquáticas, o que resulta em inúmeros problemas relacionados à qualidade da água, bem como aos seus usos múltiplos. Dentre os diversos problemas causados pela presença em excesso dessas plantas, podem ser citados: obstrução de turbinas e grades de proteção de hidrelétricas, funcionamento anormal de eclusas, redução da biodiversidade, entrave à navegação, habitat de vetores de várias doenças, além do prejuízo às atividades de lazer (Martins et al., 2003, 2008, 2009; Carvalho et al., 2005).

Ressalta-se que a maior disponibilidade de nutrientes observada em ambientes aquáticos perturbados tem favorecido a produção de grande quantidade de biomassa pelas plantas aquáticas. Em consequência, isso pode acarretar maior consumo de oxigênio, pelo aumento do teor de matéria orgânica através de sua decomposição, além de haver desequilíbrios ecológicos, os quais podem ser observados no curto prazo, como a morte de peixes pela redução de oxigênio na água.

A colonização de plantas aquáticas em corpos hídricos poluídos tem sido intensa devido ao predomínio de condições favoráveis ao crescimento, em função do incremento na concentração de nutrientes, além dos fatores vitais ao desenvolvimento da população, bem como à ausência de predadores. Atualmente, os impactos causados por atividades antrópicas têm se tornado frequentes, a exemplo do Pantanal mato-grossense, no qual o rio Taquari foi submetido a um processo de assoreamento, devido ao aumento da quantidade de sedimento proveniente da intensa erosão, principalmente nos solos arenosos. Esse fato afeta mais de $11.000 \mathrm{~km}^{2}$ de planícies, o que acarreta alterações drásticas na hidrologia e, por consequência, também altera a fauna e a flora (Pott \& Pott, 2004).

Brachiaria subquadripara é uma planta aquática perene que facilmente coloniza ambientes úmidos, sobretudo nas margens de corpos hídricos e quando disseminada em locais próximos a áreas de arroz irrigado. Também, pode ser considerada uma planta infestante, pois apresenta alta eficiência na utilização de recursos e crescimento rápido, bem como resistência a inundações temporárias, o que confere sua agressividade na colonização do ambiente (Kissmann, 1997).

O reservatório de Barra Bonita é considerado o mais antigo entre aqueles do complexo de hidrelétricas da bacia hidrográfica do rio Tietê e ocupa uma área de intensas transformações nos padrões de uso e ocupação da terra, com problemas de poluição, sendo a água destinada a usos múltiplos. A região circunvizinha ao reservatório apresenta-se como uma das mais populosas e desenvolvidas do interior de São Paulo, com grandes aglomerações urbanas (Prado, 2004).

Cavenaghi (2003) avaliou algumas características da água e do sedimento em relação ao ambiente de ocorrência de plantas aquáticas em reservatórios da bacia do rio Tietê e verificou que no reservatório de Barra Bonita havia grandes infestações de $B$. subquadripara, a qual foi considerada a principal espécie competidora desse ambiente, com valor de importância de 16,08\%. No entanto, existem poucos estudos que relacionam a ocorrência das populações de $B$. subquadripara com fatores abióticos do meio, uma vez que essa espécie é considerada um problema em vários reservatórios da bacia hidrográfica do rio Tietê.

O presente trabalho objetivou realizar o monitoramento das populações de $B$. subquadripara em função da variação sazonal de algumas características do seu ambiente de ocorrência. 


\section{MATERIAL E MÉTODOS}

A seleção desse reservatório para a realização do presente estudo teve como principais fundamentos a alta frequência relativa de $B$. subquadripara, observada em estudos realizados por Cavenaghi (2003). Além disso, a bacia hidrográfica de contribuição para o reservatório de Barra Bonita é constituída por parte das bacias hidrográficas Piracicaba/ Capivari/Jundiaí (BHPCJ) e Tietê/Sorocaba (BHTS), ambas no Estado de São Paulo, correspondendo a uma área total de aproximadamente $19.000 \mathrm{~km}^{2}$. Ela está inserida entre as coordenadas geográficas de $21^{\circ} 54^{\prime} 20^{\prime \prime}$ e $23^{\circ} 57^{\prime} 26^{\prime \prime}$ sul e $46^{\circ} 39^{\prime} 27^{\prime \prime}$ e $48^{\circ} 34^{\prime} 52^{\prime \prime}$ WGr. (Prado, 2004).

O trabalho de caracterização da qualidade da água, sedimento, solos das margens e levantamento de populações de $B$. subquadripara teve início com o reconhecimento prévio da área de estudo no reservatório Barra Bonita, pertencente à bacia hidrográfica do rio Tietê. Assim, no dia 25 de maio de 2004 foram percorridas as margens dos rios Tietê e Piracicaba, para demarcação de pontos de coleta, com um GPS 12 marca Garmin, os quais apresentavam áreas colonizadas por estandes representativos de B. subquadripara.

O reservatório de Barra Bonita - construído a partir do represamento dos rios Tietê e Piracicaba, bem como de vários afluentes está localizado a jusante da cidade de São Paulo (aproximadamente $300 \mathrm{~km}$ ), entre os municípios de Barra Bonita e Igaraçu do Tietê. Essa região caracteriza-se por ser de transição entre os climas tropicais e subtropicais e as estações anuais são bem definidas, segundo a classificação de Köppen, sendo do tipo CWA (clima mesotérmico), com inverno seco e verão quente (Monteiro, 1973).

$\mathrm{O}$ monitoramento dos fatores ambientais referente ao habitat da espécie foi realizado em duas épocas: estação seca e das águas, as quais foram correspondentes às campanhas de coleta de julho a setembro de 2004 e janeiro a março de 2005. As coletas iniciaram-se nos dias 6 de julho de 2004 e 14 de janeiro de 2005 nos pontos previamente selecionados e georreferenciados, os quais se constituíram de 13 pontos dentro do reservatório Barra Bonita (sete pontos no braço do rio Piracicaba e seis no braço do rio Tietê), que estão representados na Tabela 1. Assim, nesta área realizaramse em cada época: 26 amostras de solo (13 do solo da margem do rio e 13 do sedimento do fundo do lago), 26 amostras de água (duas repetições para cada ponto, para obter o valor médio do local amostrado) e 13 amostras do estande de plantas, que, em conjunto, subsidiaram o estudo de caracterização do ambiente de ocorrência da espécie em estudo.

A amostragem de solo foi realizada com a coleta de material na margem do rio com o auxílio de um enxadão; após a limpeza da camada superficial, retiraram-se $20 \mathrm{~cm}$ de perfil do solo desde a parte seca até a úmida, bem como procedeu-se à coleta do solo submerso (sedimento) próximo à margem (2 a $3 \mathrm{~m}$ ), por meio de uma draga manual (tipo Petersen). Analisaram-se as seguintes características: $\mathrm{pH}$, capacidade de troca de cátions (CTC), soma por bases (SB), saturação por bases (V\%) e textura, além dos teores de matéria orgânica ( $\mathrm{MO} \%), \mathrm{Ca}, \mathrm{Mg}, \mathrm{P}, \mathrm{K}, \mathrm{N}$ total, S e H + Al.

As coletas das amostras de água foram realizadas com o auxílio de frascos de plástico fosco, a uma profundidade aproximada de $10 \mathrm{~cm}$ abaixo da superficie, para evitar a contaminação da amostra por restos de materiais vegetais presentes na superficie. Esses frascos foram acondicionados em caixas de isopor contendo gelo, para conservação da amostra durante o transporte até o laboratório. A determinação dos parâmetros físicos, como $\mathrm{pH}$, temperatura, turbidez e condutividade elétrica, foi realizada no ambiente de coleta em temperatura ambiente, com auxílio de um phmetro e termômetro marca Corning, condutivimetro marca Hanna Instruments modelo HI 99300 e turbidimetro marca Hanna Instruments modelo HI 93703. As análises químicas realizadas em laboratório constituíram-se de teores de nitrato, nitrito, amônia, sulfato, fosfato e teores dissolvidos de $\mathrm{Ca}, \mathrm{Mg}$ e K.

A amostragem das plantas foi feita de acordo com o método do quadrado de madeira de $0,25 \mathrm{~m}^{2}$, o qual foi lançado de forma aleatória sobre um estande homogêneo de plantas. Assim, a biomassa emersa (parte aérea da planta na superfície da água) presente no 
Tabela 1 - Localização geográfica e descrição dos pontos de coleta no reservatório de Barra Bonita-SP, referente aos períodos de monitoramento do ambiente de ocorrência da espécie

\begin{tabular}{|c|c|c|c|c|c|}
\hline Ponto & Latitude & Longitude & Norte (UTM) & Leste (UTM) & Descrição \\
\hline 003 & $\mathrm{~S} 22^{\circ} 46^{\prime} 3,51^{\prime \prime}$ & W 48 $09^{\prime} 40,72^{\prime \prime}$ & 791.493 & 7.479 .406 & Rio Tietê/ponte (Anhembi) \\
\hline 004 & S $22^{\circ} 44^{\prime} 1,73^{\prime \prime}$ & W 4809'59,35" & 791.033 & 7.483 .164 & Rio Tietê \\
\hline 006 & $\mathrm{~S} 22^{\circ} 42^{\prime} 50,49^{\prime \prime}$ & W $48^{\circ} 10^{\prime} 44,53^{\prime \prime}$ & 789.785 & 7.485 .381 & Rio Tietê \\
\hline 009 & $\mathrm{~S} 22^{\circ} 42^{\prime} 27,69^{\prime \prime}$ & W 48 $12^{\prime} 58,57^{\prime \prime}$ & 785.971 & 7.486 .155 & Rio Tietê \\
\hline 011 & S 22०39'33,88" & W $48^{\circ} 16^{\prime} 39,86^{\prime \prime}$ & 779.751 & 7.491 .621 & Rio Tietê \\
\hline 013 & $\mathrm{~S} 22^{\circ} 40^{\prime} 32,32^{\prime \prime}$ & W 48 $20^{\prime} 5,35^{\prime \prime}$ & 773.850 & 7.489 .929 & Rio Tietê/Rio Bonito \\
\hline 014 & $\mathrm{~S} 22^{\circ} 36^{\prime} 57,58^{\prime \prime}$ & W $48^{\circ} 17^{\prime} 55,22^{\prime \prime}$ & 777.686 & 7.496 .470 & Rio Piracicaba \\
\hline 019 & $\mathrm{~S} 22^{\circ} 37^{\prime} 32,73^{\prime \prime}$ & W48 $13^{\prime} 9,64^{\prime \prime}$ & 785.825 & 7.495 .238 & Rio Piracicaba \\
\hline 020 & $\mathrm{~S} 22^{\circ} 38^{\prime} 26,43^{\prime \prime}$ & W 48 $10^{\prime} 5,30^{\prime \prime}$ & 791.060 & 7.493 .486 & Rio Piracicaba \\
\hline 016 & S $22^{\circ} 35^{\prime} 7,46^{\prime \prime}$ & W $48^{\circ} 15^{\prime} 3,77^{\prime \prime}$ & 782.647 & 7.499 .769 & Rio Piracicaba \\
\hline 023 & $\mathrm{~S} 22^{\circ} 36^{\prime} 50,58^{\prime \prime}$ & 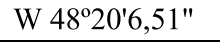 & 773.939 & 7.496 .753 & Rio Piracicaba \\
\hline 026 & S 22 $31^{\prime} 30,96^{\prime \prime}$ & W 4828'23,52" & 759.907 & 7.506 .835 & Rio Piracicaba \\
\hline 028 & S $22^{\circ} 32^{\prime} 1,17^{\prime \prime}$ & W 4831'13,73" & 755.026 & 7.505 .987 & Rio Tietê/(barragem) \\
\hline
\end{tabular}

Zona (UTM) da localização geográfica $-22 \mathrm{~K}$.

interior dessa área predefinida foi coletada com o auxílio de um facão e uma tesoura de poda e, em seguida, acondicionada em sacos plásticos, para transporte até o processamento das amostras em laboratório. A área infestada da população de $B$. subquadripara foi estimada por avaliação visual do comprimento e largura da área ocupada pela espécie no ponto amostrado.

As plantas foram colocadas para secar em estufa de circulação forçada de ar a $65{ }^{\circ} \mathrm{C}$ até atingirem peso constante (72 horas). Após a realização desse processo, obteve-se a massa seca coletada na área de $0,25 \mathrm{~m}^{2}$, para cálculo da densidade de plantas da população em cada ponto, a qual foi expressa em $\mathrm{g} \mathrm{m}^{-2}$. A partir dessa amostra, foi retirada uma subamostra, em quantidade suficiente para a análise química da determinação dos macronutrientes. A determinação das concentrações de $\mathrm{N}$ foi obtida por titulometria após a destilação, enquanto para os outros macronutrientes utilizou-se espectrometria de plasma. $\mathrm{O}$ acúmulo de macronutrientes na parte aérea das plantas coletadas no reservatório Barra Bonita, expresso em $\mathrm{g} \mathrm{m}^{-2}$, foi relacionado com a densidade populacional.

\section{RESULTADOS E DISCUSSÃO}

A distribuição das populações de B. subquadripara em relação à área de infestação foi considerada heterogênea entre os pontos amostrados no reservatório de Barra Bonita, principalmente no verão (Tabela 2). Na Tabela 3, observa-se que no inverno a área da população apresentou menor amplitude de variação $\left(50\right.$ a $\left.1.000 \mathrm{~m}^{2}\right)$ entre os pontos amostrados do que a registrada no verão (2 a $20.000 \mathrm{~m}^{2}$ ). Registra-se também que, entre o verão e o inverno, os pontos 3, 4 e 9 apresentaram redução na área colonizada pela espécie correspondente a 25,0, 98,7 e 14,3\%, respectivamente (Tabelas 2 e 3 ).

A extensão da área da população de plantas depende de condições favoráveis ao crescimento dessa espécie, a qual possui origem em clima tropical. Ressalta-se que a temperatura adequada para a absorção de nutrientes constitui-se em um fator importante para o crescimento das plantas, uma vez que também pode influenciar na eficiência biológica expressa pela conversão dos recursos absorvidos (luz e nutrientes) em biomassa.

Essas condições climáticas favoráveis ao crescimento das plantas dessa espécie contribuíram para o aumento da área de infestação observada no verão (Tabela 2). Notase que, nessa estação, as maiores áreas de infestação foram encontradas nos pontos 13, 6, 20, 11 e 23; no entanto, quanto à densidade $\left(\mathrm{kg} \mathrm{m}^{-2}\right)$, destacaram-se os pontos $26,28,6,19$ e 11. A massa seca produzida estimada nas 
áreas infestadas foi verificada em maior quantidade nos pontos $13,6,20,11$ e 23, os quais apresentaram o equivalente a 11,$0 ; 4,7$; 4,$5 ; 2,1$; e 1,7 toneladas na área infestada, respectivamente.

No inverno (Tabela 3), as maiores áreas de infestação foram encontradas nos pontos $13,20,6,9$ e 16 , os quais também apresentaram maiores quantidades de massa seca na área de infestação.

A análise do estado nutricional da parte aérea das plantas quanto aos principais macronurtrientes avaliados nas diferentes populações amostradas nos rios Tietê e Piracicaba, tanto no inverno como no verão, é apresentada na Tabela 4. A faixa de teores de nutrientes $\mathrm{kg}^{-1}$ : (N-13 a 20; P- 0,8 a 3,0; K - 12 a 30) adequados para B. brizantha, segundo Werner et al. (1986), subsidiou a interpretação da análise de nutrientes dessa espécie de planta aquática. Quanto ao nitrogênio, independentemente da época, a maioria das populações amostradas apresentou teores acima desse padrão de referência, exceto para as populações dos pontos 26 e 28 referentes à época do verão. Já para os teores de fósforo e potássio, todas as populações mostraram valores adequados para gramíneas, sendo encontrados teores em

Tabela 2 - Valores médios da massa seca emersa de plantas de Brachiaria subquadripara produzida na área infestada e estimada no verão. Reservatório de Barra Bonita-SP, 2005

\begin{tabular}{|r|c|r|c|r|}
\hline \multirow{2}{*}{ Ponto } & \multicolumn{2}{|c|}{ Área da população } & \multicolumn{2}{c|}{ Massa seca } \\
\cline { 2 - 5 } & $(\mathrm{C} \times \mathrm{L})$ & $\left(\mathrm{m}^{2}\right)$ & $\left(\mathrm{kg} \mathrm{m}^{-2}\right)$ & $\left(\mathrm{kg} \mathrm{área}^{-1}\right)$ \\
\hline 3 & $15 \times 5$ & 75 & 0,400 & 29,98 \\
\hline 4 & $2 \times 1$ & 2 & 0,130 & 0,26 \\
\hline 6 & $40 \times 200$ & 8.000 & 0,593 & $4.745,28$ \\
\hline 9 & $20 \times 15$ & 300 & 0,450 & 135,00 \\
\hline 11 & $20 \times 150$ & 3.000 & 0,700 & $2.100,79$ \\
\hline 13 & $100 \times 200$ & 20.000 & 0,551 & $11.016,47$ \\
\hline 14 & $5 \times 10$ & 50 & 0,532 & 26,60 \\
\hline 16 & $30 \times 10$ & 300 & 0,351 & 105,36 \\
\hline 19 & $30 \times 50$ & 1.500 & 0,768 & $1.151,29$ \\
\hline 20 & $200 \times 40$ & 8.000 & 0,567 & $4.533,65$ \\
\hline 23 & $20 \times 150$ & 3.000 & 0,577 & $1.732,32$ \\
\hline 26 & $5 \times 30$ & 150 & 0,901 & 135,13 \\
\hline 28 & $20 \times 60$ & 1.200 & 0,735 & 882,14 \\
\hline
\end{tabular}

$\mathrm{C}=$ comprimento. $\mathrm{L}=$ largura . excesso na biomassa das populações nos pontos 6 e 9 .

Contudo, estudos realizados em laboratório e em ambiente natural com plantas aquáticas têm revelado a importância das variações entre espécies na concentração de nutrientes, a qual também pode ser alterada pela estação climática, idade da planta e estádio de crescimento. Aláez et al. (1999) sugeriram, como uma rápida análise do estado nutricional dessas plantas, que os valores de 1,3 e $0,13 \%$ da biomassa podem ser considerados, de maneira geral, como concentrações críticas de $\mathrm{N}$ e $\mathrm{P}$, respectivamente, para todas as plantas aquáticas. A concentração crítica de nutrientes na planta pode ser definida como a concentração no tecido da planta que permite a produção máxima. Assim, em relação a esses níveis criticos citados, pode-se inferir que as plantas de todas as populações amostradas apresentaram absorção excessiva de N. Essa afirmativa pode ser constatada quanto aos acúmulos de $\mathrm{N}$ na biomassa coletada no rio Tietê, os quais resultaram em incrementos de 44,2 a $53,1 \%$ na época do inverno e de 47,2 a $67,3 \%$ na do verão, exceto para a população do ponto 28 , que apresentou redução de $83 \%$, sempre em ordem decrescente, com o caminhamento em direção à barragem. Já em

Tabela 3 - Valores médios da massa seca emersa de plantas de Brachiaria subquadripara produzida na área infestada e estimada no inverno. Reservatório Barra Bonita-SP, 2004

\begin{tabular}{|c|c|c|c|c|}
\hline \multirow{2}{*}{ Ponto } & \multicolumn{2}{|c|}{ Área da população } & \multicolumn{2}{c|}{ Massa seca } \\
\cline { 2 - 5 } & $(\mathrm{C} \times \mathrm{L})$ & $\left(\mathrm{m}^{2}\right)$ & $\left(\mathrm{kg} \mathrm{m}^{-2}\right)$ & $\left(\mathrm{kg} \mathrm{área}^{-1}\right)$ \\
\hline 3 & $10 \times 10$ & 100 & 0,468 & 46,78 \\
\hline 4 & $15 \times 10$ & 150 & 0,413 & 62,01 \\
\hline 6 & $50 \times 10$ & 500 & 0,390 & 195,06 \\
\hline 9 & $10 \times 35$ & 350 & 0,408 & 142,74 \\
\hline 11 & $15 \times 10$ & 150 & 0,448 & 67,26 \\
\hline 13 & $100 \times 10$ & 1.000 & 0,420 & 419,50 \\
\hline 14 & $5 \times 10$ & 50 & 0,703 & 35,13 \\
\hline 16 & $20 \times 10$ & 200 & 0,754 & 150,75 \\
\hline 19 & $5 \times 10$ & 50 & 0,411 & 20,56 \\
\hline 20 & $60 \times 10$ & 600 & 0,447 & 268,25 \\
\hline 23 & $10 \times 10$ & 100 & 0,506 & 50,62 \\
\hline 26 & $10 \times 10$ & 100 & 0,362 & 36,17 \\
\hline 28 & $15 \times 10$ & 150 & 0,428 & 64,19 \\
\hline
\end{tabular}

$\mathrm{C}=$ comprimento. $\mathrm{L}=$ largura.

Planta Daninha, Viçosa-MG, v. 29, n. 1, p. 37-49, 2011 
relação às populações do rio Piracicaba, observaram-se 22,6 a $50,9 \%$ no inverno e 19,8 a $48 \%$ no verão, exceto para a população do ponto 26 , em que se constatou redução de $76 \%$.

Quanto ao fósforo, observaram-se, nas populações do rio Tietê, acúmulos de 13,3 a $52,2 \%$ no inverno e 7,1 a $69,8 \%$ no verão, enquanto no rio Piracicaba a maioria das populações apresentou teores de $\mathrm{P}(-8,3$ a $62,5 \%$ ) abaixo do nivel crítico preestabelecido e não houve diferenças entre as épocas.

Aláez et al. (1999) ressaltaram que a quantidade de nutrientes acumulada depende da capacidade fisiológica para absorção de nutrientes por determinadas espécies, bem como em relação à biomassa produzida. Os pesquisadores também enfatizaram que a composição de nutrientes nos tecidos dessas plantas pode ser considerada um importante fator para identificar as estratégias ecológicas das espécies e para a predição de interações competitivas em comunidades de plantas. Jackson \& Kalff (1993) demonstraram, ainda, que a variação na concentração de macronutrientes nos tecidos de plantas aquáticas está correlacionada com a forma de crescimento destas.

Cavenaghi (2003) avaliou algumas características da água e do sedimento em

Tabela 4 - Médias dos teores de macronutrientes presentes na massa seca emersa de plantas de Brachiaria subquadripara coletada na população encontrada na época do inverno e verão. Reservatório de Barra Bonita-SP, 2004/05

\begin{tabular}{|c|c|c|c|c|c|c|}
\hline \multirow{3}{*}{ Ponto } & \multicolumn{3}{|c|}{$\mathrm{N}$} & \multicolumn{2}{c|}{$\mathrm{P}$} & \multicolumn{2}{c|}{$\mathrm{K}$} \\
\cline { 2 - 7 } & \multicolumn{7}{|c|}{$\left(\mathrm{g} \mathrm{kg}^{-1}\right)$} \\
\cline { 2 - 7 } & Inverno & Verão & Inverno & Verão & Inverno & Verão \\
\hline 3 & 27,7 & 39,8 & 2,9 & 1,8 & 29,8 & 39,2 \\
\hline 4 & 26,0 & 34,5 & 2,2 & 4,3 & 27,3 & 38,0 \\
\hline 6 & 27,6 & 34,3 & 2,0 & 1,8 & 31,8 & 29,8 \\
\hline 9 & 36,9 & 27,5 & 2,5 & 1,4 & 31,4 & 27,6 \\
\hline 11 & 23,3 & 24,4 & 1,5 & 1,5 & 26,0 & 27,9 \\
\hline 13 & 26,1 & 24,6 & 1,5 & 2,0 & 18,3 & 25,1 \\
\hline 14 & 17,1 & 23,9 & 1,1 & 1,2 & 20,8 & 34,0 \\
\hline 16 & 26,5 & 25,0 & 1,2 & 1,1 & 23,0 & 28,6 \\
\hline 19 & 21,3 & 16,2 & 0,9 & 0,8 & 26,9 & 32,1 \\
\hline 20 & 16,8 & 23,8 & 0,8 & 1,6 & 22,4 & 31,9 \\
\hline 23 & 25,7 & 17,4 & 1,0 & 1,2 & 28,1 & 14,8 \\
\hline 26 & 19,3 & 7,4 & 1,2 & 0,9 & 27,8 & 7,9 \\
\hline 28 & 24,7 & 7,1 & 0,9 & 2,4 & 21,3 & 29,8 \\
\hline
\end{tabular}

relação ao ambiente de ocorrência de plantas aquáticas em reservatórios da bacia do rio Tietê e verificou que, no reservatório de Barra Bonita, havia grandes infestações de B. subquadripara, a qual foi considerada a principal espécie competidora desse ambiente, com valor de importância de $16,08 \%$. Em estudos de levantamento prévio na bacia do rio Tietê, o pesquisador observou, entre os reservatórios desse rio, que essa espécie segue uma ordem decrescente de ocorrência a partir de Barra Bonita até o reservatório Três Irmãos; esse fato pode estar relacionado com o grau de eutrofização de cada reservatório, sendo observada frequência relativa dessa espécie $(14,9 ; 19,0 ; 13,4 ; 9,8 ; 3,3$; e 0,019\%) sempre em alta densidade populacional em Barra Bonita, Bariri, Ibitinga, Promissão, Nova Avanhandava e Três Irmãos, respectivamente.

Os resultados das análises de solo e sedimento nas duas épocas avaliadas (Tabelas 5, 6, 7 e 8) foram comparados a valores recomendados para gramíneas anuais em solos agrícolas (Raij et al., 1997). A análise da composição do solo das margens e do sedimento revelou na maioria dos pontos amostrados condições de alta acidez $(3,7$ a 4,6), com exceção dos pontos 3 e 14 , nos quais foi observado um caráter básico no sedimento $(6,3$ e 7,2, respectivamente) na estação seca. Ressalta-se o elevado nível de fertilidade verificado tanto nos solos da margem dos rios quanto no sedimento referente à maioria dos pontos analisados nas duas épocas. Na região do reservatório de Barra Bonita predominam as classes de solos referentes a Latossolo Vermelho distroférrico e Nitossolo Vermelho distroférrico, ambos provenientes de rocha alcalina (basalto) da formação Serra Geral, e Latossolo Vermelho-Amarelo distrófico e Argissolo Vermelho-Amarelo distrófico, provenientes da formação Botucatu (Cavenaghi, 2003), o que pode explicar em parte os valores de $\mathrm{pH}$ encontrados.

Quanto aos solos da margem dos rios, percebe-se a distinção de niveis de fertilidade entre os pontos amostrados quando são considerados os valores de saturação por bases. Assim, foram associados os pontos segundo os niveis de fertilidade definidos em ordem decrescente, de acordo com a classificação: na estação seca (> 90\%) - pontos 3, 4, 
Fatores ambientais na distribuição de populações de ...

Tabela 5 - Análise química das amostras de solo coletadas nas margens, referente à época seca (inverno). Reservatório de Barra Bonita-SP, 2004

\begin{tabular}{|c|c|c|c|c|c|c|c|c|c|c|}
\hline \multirow{2}{*}{ Ponto } & \multirow{2}{*}{$\begin{array}{c}\mathrm{pH} \\
(\mathrm{CaCl}) \\
\end{array}$} & \multirow{2}{*}{$\begin{array}{c}\text { M.O. } \\
\left(\mathrm{g} \mathrm{kg}^{-1}\right) \\
\end{array}$} & \multirow{2}{*}{$\begin{array}{c}\text { P resina } \\
\left(\mathrm{mg} \mathrm{dm}^{-3}\right)\end{array}$} & $\mathrm{H}+\mathrm{Al}$ & $\mathrm{K}$ & $\mathrm{Ca}$ & $\mathrm{Mg}$ & SB & CTC & \multirow{2}{*}{$\begin{array}{c}\mathrm{V} \\
(\%)\end{array}$} \\
\hline & & & & \multicolumn{6}{|c|}{$\left(\mathrm{mmol}_{\mathrm{c}} \mathrm{dm}^{-3}\right)$} & \\
\hline 3 & 5,6 & 16,6 & 33,6 & 2,2 & 2,8 & 89,0 & 32,0 & 123,8 & 126,0 & 98,2 \\
\hline 4 & 4,9 & 25,0 & 15,1 & 3,0 & 3,9 & 16,2 & 12,8 & 32,9 & 35,9 & 91,7 \\
\hline 6 & 4,0 & 37,5 & 14,8 & 7,5 & 0,8 & 8,1 & 1,0 & 9,9 & 17,4 & 57,1 \\
\hline 9 & 4,1 & 16,6 & 6,5 & 3,5 & 0,8 & 6,1 & 1,8 & 8,7 & 12,2 & 71,3 \\
\hline 11 & 5,0 & 28,1 & 21,2 & 3,0 & 3,4 & 28,3 & 8,4 & 40,1 & 43,0 & 93,1 \\
\hline 13 & 6,6 & 21,7 & 44,6 & 1,2 & 2,3 & 34,4 & 12,0 & 48,7 & 49,9 & 97,5 \\
\hline 14 & 4,5 & 18,6 & 9,1 & 2,6 & 1,6 & 4,0 & 3,8 & 9,5 & 12,1 & 78,4 \\
\hline 16 & 4,6 & 23,0 & 15,3 & 3,6 & 2,9 & 10,1 & 3,4 & 16,5 & 20,1 & 82,0 \\
\hline 19 & 3,9 & 19,3 & 7,3 & 5,0 & 1,2 & 2,0 & 0,4 & 3,6 & 8,6 & 42,0 \\
\hline 20 & 4,6 & 17,4 & 6,9 & 2,2 & 2,1 & 6,1 & 1,8 & 10,0 & 12,2 & 81,6 \\
\hline 23 & 4,0 & 13,1 & 3,8 & 3,4 & 1,3 & 4,0 & 1,4 & 6,7 & 10,1 & 66,4 \\
\hline 26 & 4,5 & 18,8 & 5,2 & 2,8 & 2,1 & 6,1 & 2,6 & 10,8 & 13,6 & 79,2 \\
\hline 28 & 4,7 & 31,2 & 20,2 & 3,5 & 2,4 & 72,8 & 2,6 & 77,8 & 81,4 & 95,7 \\
\hline
\end{tabular}

Tabela 6 - Análise química das amostras de solo coletadas na margem, referente à época das águas (verão). Reservatório de Barra Bonita-SP, 2005

\begin{tabular}{|c|c|c|c|c|c|c|c|c|c|c|}
\hline \multirow{2}{*}{ Ponto } & \multirow{2}{*}{$\frac{\mathrm{pH}}{(\mathrm{CaCl})}$} & \multirow{2}{*}{$\frac{\text { M.O. }}{\left(\mathrm{g} \mathrm{kg}^{-1}\right)}$} & \multirow{2}{*}{$\begin{array}{c}\text { P resina } \\
\left(\mathrm{mg} \mathrm{dm}^{-3}\right)\end{array}$} & $\mathrm{H}+\mathrm{Al}$ & $\mathrm{K}$ & $\mathrm{Ca}$ & $\mathrm{Mg}$ & SB & CTC & \multirow{2}{*}{$\frac{\mathrm{V}}{(\%)}$} \\
\hline & & & & \multicolumn{6}{|c|}{$\left(\mathrm{mmol}_{\mathrm{c}} \mathrm{dm}^{-3}\right)$} & \\
\hline 3 & 5,7 & 12,0 & 60,0 & 19,0 & 4,0 & 177,0 & 46,0 & 228,0 & 247,0 & 92,0 \\
\hline 4 & 3,7 & 11,9 & 8,6 & 23,8 & 2,2 & 7,1 & 5,8 & 15,1 & 38,8 & 38,7 \\
\hline 6 & 3,9 & 16,0 & 2,3 & 5,0 & 1,7 & 4,0 & 1,0 & 6,7 & 11,7 & 57,3 \\
\hline 9 & 4,0 & 14,3 & 2,7 & 1,9 & 0,5 & 3,0 & 1,0 & 4,5 & 6,5 & 69,9 \\
\hline 11 & 3,7 & 10,6 & 0,9 & 30,6 & 1,1 & 4,0 & 1,2 & 6,3 & 36,9 & 17,1 \\
\hline 13 & 5,0 & 12,1 & 24,7 & 1,1 & 2,5 & 7,1 & 3,4 & 13,0 & 14,1 & 91,9 \\
\hline 14 & 4,4 & 10,6 & 1,3 & 0,9 & 0,1 & 1,0 & 0,2 & 1,3 & 2,3 & 58,9 \\
\hline 16 & 4,2 & 13,1 & 15,9 & 2,4 & 0,2 & 2,0 & 0,2 & 2,4 & 4,8 & 49,8 \\
\hline 19 & 3,9 & 18,9 & 2,4 & 5,6 & 0,2 & 2,0 & 0,4 & 2,7 & 8,3 & 32,2 \\
\hline 20 & 4,6 & 10,9 & 1,5 & 1,2 & 2,3 & 3,0 & 1,2 & 6,5 & 7,7 & 84,8 \\
\hline 23 & 4,9 & 11,5 & 2,0 & 1,2 & 0,2 & 3,0 & 0,8 & 4,1 & 5,3 & 77,3 \\
\hline 26 & 4,7 & 10,4 & 2,0 & 0,9 & 0,1 & 5,1 & 1,0 & 6,1 & 7,0 & 87,1 \\
\hline 28 & 4,5 & 44,1 & 21,4 & 13,0 & 5,6 & 41,5 & 1,0 & 48,1 & 61,1 & 78,7 \\
\hline
\end{tabular}

11, 13 e 28; (71 a 80\%) - pontos 9, 14, 20 e 26; (41 a 70\%) - pontos 4, 19 e 23 (Tabela 5); na estação das águas (> 90\%) - pontos 3 e 13; (71 a $80 \%$ ) - pontos 20, 23, 26 e 28; (41 a 70\%) pontos 6, 9, 14 e 16; e (17 a 40\%) - pontos 4, 11 e 19 (Tabela 6).

Nota-se que a variação sazonal influenciou no nível de fertilidade dos pontos amostrados, uma vez que na estação das águas a maioria dos pontos foi classificada em grupos, segundo a saturação por bases $<70 \%$.

Para os valores de $\mathrm{P}$, Ca e Mg, considerouse como teores altos de 41 a $80 \mathrm{mg} \mathrm{dm}^{3}$, de 4 a $7 \mathrm{mmol}_{\mathrm{c}} \mathrm{dm}^{-3}$ e de 5 a $8 \mathrm{mmol}_{\mathrm{c}} \mathrm{dm}^{-3}$, respectivamente. Verificou-se que teores altos de fósforo foram registrados apenas nos pontos 13 e 3, referentes ao inverno e verão, respectivamente. No entanto, os teores médios de 15 a 
$40 \mathrm{mg} \mathrm{dm}^{-3}$ foram predominantes no inverno entre os pontos 3, 4, 11, 16 e 28. Já em relação ao verão os teores médios foram observados apenas nos pontos 16 e 28; quanto aos demais pontos, verificaram-se teores baixos de fósforo (<15 $\left.\mathrm{mg} \mathrm{dm}^{-3}\right)$.

Para o cálcio, observaram-se teores muito altos nos pontos 3,11,13, 16 e 28; no verão, encontraram-se valores na faixa de médio a baixo nos solos referentes aos pontos 9, 14, $16,19,20$ e 23. Quanto ao magnésio, também foram verificados valores muito altos nos pontos 3 , 4 e 11 ; no verão, apenas o ponto 3 apresentou alto teor de $\mathrm{Mg}$, e na maioria dos pontos constataram-se teores baixos.

A taxa de matéria orgânica no sedimento pode alterar a habilidade das plantas aquáticas em oxigenar as raizes; assim, mais que 5\% (peso seco) da matéria orgânica no sedimento pode inibir o crescimento de algumas espécies submersas, como Elodea canadensis, Hydrilla verticillata e Myriophyllum aquaticum, as quais são mais sensiveis nesse aspecto do que as plantas emergentes (Barko \& Smart, 1983, 1986; Barko et al., 1986). Embora a elucidação para esse fato ainda não tenha sido comprovada, os pesquisadores sugeriram que a inibição do crescimento pode ser o resultado do acúmulo de compostos fitotóxicos durante a decomposição anaeróbica do carbono orgânico.
No entanto, a maioria dos pontos amostrados apresentou altos teores de matéria orgânica, sendo observados teores menores que $1,3 \%$ nas amostras de sedimentos dos pontos 9 e 26 na época do inverno (Tabela 7) e 9, 4, 11, 20 e 23 na época do verão (Tabela 8). Contudo, os altos teores de matéria orgânica observados não influenciaram no desenvolvimento das populações de $B$. subquadripara.

Quanto ao $\mathrm{pH}$ do sedimento, observou-se caráter mais ácido do que em relação ao $\mathrm{pH}$ do solo das margens, exceto para os pontos 3,11 e $23(\mathrm{pH}>5,5)$. No entanto, em condições de $\mathrm{pH}$ baixo no sedimento, pode causar niveis fitotóxicos de alguns metais (manganês e alumínio), sendo ainda reduzida a disponibilidade de $\mathrm{CO}_{2}$ dissolvido e de outros nutrientes (cálcio e magnésio), enquanto o $\mathrm{pH}$ alto pode reduzir a disponibilidade de fosfato, sulfato, ferro e manganês (Jackson \& Kalff, 1993).

Assim, o estado oxidado ou reduzido dos sedimentos constitui-se em um fator essencial na regulação do fluxo de nutrientes e do oxigênio liberado pelas raízes das plantas aquáticas, o qual é o principal fator de estabilização contra a liberação de nutrientes e toxicidade de sulfito (Giusti \& Libelli, 2005). Portanto, as raízes das plantas aquáticas marginais podem contribuir para o estado de oxirredução dos sedimentos, bem como para acidificação ou alcalinidade em função dos exsudatos radiculares.

Tabela 7 - Análise química das amostras de solo submerso (sedimento) coletadas próximo à margem, referente à época seca (inverno). Reservatório de Barra Bonita-SP, 2004

\begin{tabular}{|c|c|c|c|c|c|c|c|c|c|c|}
\hline \multirow{2}{*}{ Ponto } & \multirow{2}{*}{$\begin{array}{c}\mathrm{pH} \\
(\mathrm{CaCl}) \\
\end{array}$} & \multirow{2}{*}{$\begin{array}{c}\text { M.O. } \\
\left(\mathrm{g} \mathrm{kg}^{-1}\right)\end{array}$} & \multirow{2}{*}{$\begin{array}{c}\text { P resina } \\
\left(\mathrm{mg} \mathrm{dm}^{-3}\right)\end{array}$} & $\mathrm{H}+\mathrm{Al}$ & $\mathrm{K}$ & $\mathrm{Ca}$ & $\mathrm{Mg}$ & SB & CTC & \multirow{2}{*}{$\begin{array}{c}\mathrm{V} \\
(\%) \\
\end{array}$} \\
\hline & & & & \multicolumn{6}{|c|}{$\left(\mathrm{mmol}_{\mathrm{c}} \mathrm{dm}^{-3}\right)$} & \\
\hline 3 & 6,30 & 17,00 & 94,65 & 1,61 & 2,28 & 14,16 & 32,00 & 48,44 & 50,05 & 96,79 \\
\hline 4 & 4,75 & 22,85 & 11,56 & 3,39 & 2,10 & 16,19 & 7,60 & 25,89 & 29,28 & 88,42 \\
\hline 6 & 4,15 & 26,17 & 11,29 & 5,80 & 1,86 & 7,08 & 2,20 & 11,14 & 16,94 & 65,76 \\
\hline 9 & 4,17 & 11,73 & 4,03 & 1,41 & 0,24 & 4,05 & 1,60 & 5,89 & 7,30 & 80,63 \\
\hline 11 & 7,24 & 29,68 & 70,45 & 0,93 & 3,00 & 21,25 & 13,80 & 38,05 & 38,97 & 97,62 \\
\hline 13 & 4,15 & 24,02 & 28,50 & 5,99 & 1,20 & 12,14 & 5,80 & 19,14 & 25,13 & 76,18 \\
\hline 14 & 4,15 & 14,07 & 3,23 & 1,86 & 0,78 & 2,02 & 0,80 & 3,60 & 5,46 & 65,95 \\
\hline 16 & 4,39 & 16,80 & 3,76 & 2,66 & 0,24 & 3,04 & 0,40 & 3,68 & 6,34 & 58,00 \\
\hline 19 & 3,76 & 23,05 & 6,05 & 5,99 & 0,42 & 3,04 & 0,60 & 4,06 & 10,04 & 40,38 \\
\hline 20 & 4,14 & 12,12 & 1,75 & 1,90 & 1,08 & 3,04 & 0,80 & 4,92 & 6,81 & 72,12 \\
\hline 23 & 5,45 & 15,44 & 1,34 & 0,92 & 0,42 & 3,04 & 1,00 & 4,46 & 5,37 & 82,90 \\
\hline 26 & 4,25 & 10,75 & 1,61 & 1,25 & 0,48 & 3,04 & 0,80 & 4,32 & 5,56 & 77,58 \\
\hline 28 & 4,70 & 45,49 & 14,52 & 10,35 & 2,52 & 41,48 & 13,60 & 57,60 & 67,95 & 84,77 \\
\hline
\end{tabular}


Fatores ambientais na distribuição de populações de ...

Tabela 8 - Análise química das amostras de solo submerso (sedimento) coletadas próximo à margem, referente à época das águas (verão). Reservatório de Barra Bonita-SP, 2005

\begin{tabular}{|c|c|c|c|c|c|c|c|c|c|c|}
\hline \multirow{2}{*}{ Ponto } & $\mathrm{pH}$ & M.O. & $P$ resina & $\mathrm{H}+\mathrm{Al}$ & $\mathrm{K}$ & $\mathrm{Ca}$ & $\mathrm{Mg}$ & SB & CTC & \multirow{2}{*}{$\begin{array}{c}\mathrm{V} \\
(\%)\end{array}$} \\
\hline & $(\mathrm{CaCl})$ & $\left(\mathrm{g} \mathrm{kg}^{-1}\right)$ & $\left(\mathrm{mg} \mathrm{dm}^{-3}\right)$ & \multicolumn{6}{|c|}{$\left(\mathrm{mmol}_{\mathrm{c}} \mathrm{dm}^{-3}\right)$} & \\
\hline 3 & 5,4 & 34,0 & 96,8 & 3,1 & 2,9 & 72,8 & 17,4 & 93,2 & 96,3 & 96,7 \\
\hline 4 & 5,6 & 10,2 & 6,7 & 0,9 & 0,7 & 4,0 & 1,4 & 6,2 & 7,1 & 87,3 \\
\hline 6 & 4,2 & 41,0 & 21,8 & 9,6 & 2,3 & 10,1 & 2,6 & 15,0 & 24,6 & 60,9 \\
\hline 9 & 4,6 & 13,1 & 5,8 & 1,5 & 0,4 & 3,0 & 1,0 & 4,5 & 5,9 & 75,3 \\
\hline 11 & 4,1 & 10,2 & 1,9 & 24,8 & 1,7 & 10,1 & 2,6 & 14,4 & 39,2 & 36,7 \\
\hline 13 & 5,3 & 13,5 & 13,8 & 1,4 & 0,7 & 9,1 & 3,2 & 13,0 & 14,5 & 90,0 \\
\hline 14 & 4,5 & 13,5 & 4,4 & 1,4 & 0,3 & 3,0 & 0,8 & 4,1 & 5,5 & 75,1 \\
\hline 16 & 4,1 & 19,7 & 6,2 & 4,0 & 0,8 & 3,0 & 1,2 & 5,1 & 9,0 & 56,1 \\
\hline 19 & 4,1 & 26,4 & 7,4 & 6,6 & 1,0 & 8,1 & 2,0 & 11,1 & 17,6 & 62,7 \\
\hline 20 & 4,4 & 12,1 & 2,6 & 1,3 & 0,4 & 4,0 & 1,2 & 5,6 & 6,9 & 81,2 \\
\hline 23 & 5,2 & 10,4 & 2,3 & 0,9 & 0,6 & 5,1 & 1,4 & 7,1 & 7,9 & 89,1 \\
\hline 26 & 4,3 & 11,7 & 3,9 & 1,3 & 0,0 & 2,0 & 0,4 & 2,4 & 3,7 & 65,1 \\
\hline 28 & 4,2 & 63,3 & 34,3 & 11,6 & 1,6 & 27,3 & 5,4 & 34,3 & 46,0 & 74,7 \\
\hline
\end{tabular}

Na Tabela 9 estão apresentadas as variáveis físico-químicas monitoradas nas amostras de água do reservatório, referentes às duas épocas de amostragem (estação seca e das águas). As amostras de água coletadas no rio Tietê referentes aos pontos $3,4,6,9$, 11,13 e 28 apresentaram valores médios de pH na estação seca de 7,02 a 7,82; e na estação das águas registrou-se uma maior amplitude de variação: 6,80 a 8,0. Já no rio Piracicaba verificou-se que o $\mathrm{pH}$ da água na estação seca oscilou de 6,89 a 7,35, enquanto na estação das águas foram observados valores de 6,5 a 7,2 . Em corpos hídricos naturais, o ácido carbônico constitui-se na principal fonte de íons hidrogênio, resultando em média de $\mathrm{pH}$ de 5,7; dependendo da concentração desses ácidos, pode ocorrer redução nos valores de $\mathrm{pH}$ (Boon, 1995).

A amplitude de variação de $\mathrm{pH}$ em corpos hídricos naturais é considerada alta, porém as plantas aquáticas apresentam tolerância a essa variação; a faixa de $\mathrm{pH}$ favorável corresponde a 5,0 e 7,5, embora possam tolerar uma amplitude maior (Jackson et al., 1993). A densidade populacional estimada para $B$. subquadripara não foi influenciada pelas variações sazonais de $\mathrm{pH}$ observadas, uma vez que a menor densidade de biomassa observada no inverno provavelmente ocorreu em função de variações climáticas.
A condutividade elétrica apresentou estreita faixa de variação entre a estação das águas e seca, porém os maiores valores foram registrados entre os pontos 3 e 13, referentes ao braço do rio Tietê, e variaram de 262 a $370 \mu \mathrm{S} \mathrm{cm}^{-1}$. A condutividade média registrada nesses locais pode ser relacionada principalmente à maior concentração de cálcio, alcalinidade causada por outros compostos, e a faixa de $\mathrm{pH}$ variou de 7,04 a 7,82 e de 6,8 a 8,0 na estação seca e das águas, respectivamente.

Esse fato sugere alta salinidade e, provavelmente, constitui-se em uma consequência da poluição pelo aumento da concentração de sais na água. Onaindia et al. (1996) avaliaram a relação entre a ocorrência de plantas aquáticas e fatores ambientais em alguns rios da Espanha. Os pesquisadores encontraram altos valores de condutividade elétrica, com amplitude de 200 a $9.560 \mu \mathrm{S} \mathrm{cm}^{-1}$, e os associaram, em alguns casos, à formação de gesso e, em outros, à poluição urbana e industrial.

Os valores médios de turbidez foram mínimos na estação seca e oscilaram entre 2,31 e 5,84 NTU (Unidade Nefelométrica de Turbidez), e os máximos foram observados na estação das águas, quando foi registrada uma amplitude de 3,04 a 54,0 NTU. Esse fato implica um importante fator de redução na 
Tabela 9 - Características químicas e físicas da água nos locais de coleta durante a época seca e das águas. Reservatório de Barra Bonita-SP, 2004/05

\begin{tabular}{|c|c|c|c|c|c|c|}
\hline \multirow[b]{2}{*}{ Ponto } & \multicolumn{3}{|c|}{ Época da seca (inverno) } & \multicolumn{3}{|c|}{ Época das águas (verão) } \\
\hline & $\mathrm{pH}$ & $\begin{array}{l}\text { Condutividade } \\
\left(\mu \mathrm{S} \mathrm{cm}^{-1}\right)\end{array}$ & $\begin{array}{c}\text { Turbidez } \\
\text { (NTU) }\end{array}$ & $\mathrm{pH}$ & $\begin{array}{l}\text { Condutividade } \\
\left(\mu \mathrm{S} \mathrm{cm}^{-1}\right)\end{array}$ & $\begin{array}{c}\text { Turbidez } \\
\text { (NTU) }\end{array}$ \\
\hline 3 & 7,19 & 370 & 2,38 & 6,8 & 291 & 16,93 \\
\hline 4 & 7,08 & 330 & 3,73 & 7,2 & 245 & 5,62 \\
\hline 6 & 7,04 & 281 & 2,31 & 7,0 & 260 & 16,41 \\
\hline 9 & 7,02 & 280 & 2,40 & 8,0 & 185 & 13,55 \\
\hline 11 & 7,82 & 260 & 3,14 & 7,4 & 161 & 10,98 \\
\hline 13 & 7,34 & 262 & 3,48 & 7,3 & 183 & 3,04 \\
\hline 14 & 7,35 & 150 & 2,71 & 7,1 & 100 & 53,05 \\
\hline 16 & 6,89 & 130 & 2,85 & 7,1 & 134 & 28,28 \\
\hline 19 & 6,75 & 153 & 9,43 & 7,1 & 174 & 54,00 \\
\hline 20 & 6,96 & 140 & 4,06 & 7,3 & 130 & 48,84 \\
\hline 23 & 6,86 & 170 & 3,38 & 6,5 & 153 & 21,58 \\
\hline 26 & 6,95 & 180 & 1,37 & 7,2 & 140 & 3,35 \\
\hline 28 & 7,43 & 194 & 5,84 & 7,1 & 203 & 18,40 \\
\hline
\end{tabular}

taxa de transmissão de luz no sistema aquático. Contudo, nota-se que a turbidez não apresentou relação direta com o desenvolvimento das populações de $B$. subquadripara, pois a maior área infestada e densidade populacional (11.017 kg na área infestada) no verão foram encontradas no ponto 13 , no qual se registrou o menor valor de turbidez (3,04 NTU).

As concentrações de $\mathrm{NO}_{3}^{-}, \mathrm{NO}_{2}^{-}, \mathrm{NH}_{4}^{+}, \mathrm{N}$ total, $\mathrm{PO}_{4}^{3-}, \mathrm{SO}_{4}^{2-}, \mathrm{Ca}^{2+}, \mathrm{Mg}^{2+}$ e $\mathrm{K}^{+}$na água, correspondente à estação seca e das águas, estão apresentadas na Tabelas 10 e 11 , respectivamente. Observou-se que no rio Tietê, quanto aos teores de $\mathrm{NO}_{3}^{-}$e $\mathrm{NO}_{2}^{-}$, bem como N Total, houve redução contínua com o caminhamento em direção à barragem da UHE, independentemente da variação sazonal. A concentração de nitrogênio total frequentemente é utilizada na classificação trófica de corpos hídricos. Novo \& Leite (1996) realizaram um estudo no reservatório de Barra Bonita em agosto de 1990 (inverno) com o intuito de definir seu estado trófico, utilizando a análise dos dados limnológicos em sistemas de informação geográfica. Os pesquisadores concluíram que, em termos de disponibilidade de $\mathrm{N}$ total, o reservatório apresenta-se espacialmente heterogêneo, sendo considerado eutrófico em todo o braço do rio Tietê e corpo central do reservatório, enquanto o braço do rio Piracicaba se apresenta mesotrófico.

Quanto ao nitrogênio amoniacal, observouse ampla variação entre os pontos amostrados, sendo mais expressiva em relação aos valores extremos registrados no braço do rio Piracicaba, que oscilaram de 0,006 a 1,37 e de 0,207 a $4,82 \mathrm{mg} \mathrm{L}^{-1}$ de $\mathrm{NH}_{4}{ }^{+}$na estação seca e das águas, respectivamente. Contudo, ainda em relação à concentração de amônio, Onaindia et al. (1996) relataram que a principal via de entrada desse íon no ecossistema aquático é consequência da poluição gerada por despejos urbanos e agrícolas; altas concentrações de $\mathrm{NH}_{4}^{+}$foram correlacionadas com a ausência de plantas aquáticas, o que pode ser considerado um efeito da toxicidade desse íon. A distribuição de plantas aquáticas analisada neste estudo citado foi limitada por zonas altamente mineralizadas e eutrofizadas, as quais foram ocasionadas pela poluição industrial. Assim, em alguns casos a presença de plantas aquáticas indicou ausência de toxicidade por amônio. Onaindia et al. (1996) ressaltaram que a absorção de amônio, geralmente, causa aumento na demanda por carboidratos, o que implica maior atividade metabólica para manter o potencial osmótico intracelular. 
Existem estudos que relatam o fenômeno da hipertrofização, e isso implica possiveis transtornos no balanço químico e biológico, no qual interagem na oxidação de grande quantidade de matéria orgânica, que produz altos niveis de $\mathrm{NO}_{2}-\mathrm{e}_{4}^{+}$, os quais são tóxicos para os organismos aquáticos que toleram a eutrofização natural, bem como a liberação de energia no ecossistema. Em consequência, tem-se em uma explosão do fitoplâncton, que excede o controle realizado pelo zooplâncton e outros organismos do habitat. Assim, pode haver aumento na assimilação de $\mathrm{CO}_{2}$ pela alta densidade do fitoplâncton, que leva a um aumento no $\mathrm{pH}$ e na concentração de $\mathrm{NH}_{4}{ }^{+}$, o qual pode originar $\mathrm{NH}_{3}$, que se constitui em uma forma de nitrogênio ainda mais tóxica para organismos aquáticos (Onaindia et al., 1996).

Entretanto, estudos realizados em laboratório demonstraram que algumas espécies hidrófitas (Egeria densa, Ceratophyllum demersum e Potamogeton pectinatus) possuem potencial na absorção de $\mathrm{NH}_{4}^{+}$por meio de suas raízes e translocaram o $\mathrm{N}$ marcado para caules e folhas (Toetz, 1974).

Tabela 10 - Concentração dos macronutrientes na água, referente à época seca (inverno). Reservatório de Barra Bonita-SP, 2004

\begin{tabular}{|c|c|c|c|c|c|c|c|c|c|}
\hline \multirow{2}{*}{ Ponto } & \multicolumn{10}{|c|}{ Concentração $\left(\mathrm{mg} \mathrm{L}^{-1}\right)$} \\
\cline { 2 - 11 } & $\mathrm{NO}_{3}{ }^{-}$ & $\mathrm{NO}_{2}{ }^{-}$ & $\mathrm{NH}_{4}{ }^{+}$ & $\mathrm{N}$ total & $\mathrm{PO}_{4}{ }^{-}$ & $\mathrm{SO}_{4}{ }^{2-}$ & $\mathrm{Ca}^{2+}$ & $\mathrm{Mg}^{2+}$ & $\mathrm{K}^{+}$ \\
\hline 3 & 54,07 & 0,191 & 0,881 & 55,15 & 1,11 & 22,67 & 13,784 & 3,453 & 17,224 \\
\hline 4 & 51,79 & 0,016 & 0,078 & 51,89 & 0,97 & 22,99 & 14,073 & 3,655 & 10,748 \\
\hline 6 & 31,95 & 0,015 & 0,046 & 32,01 & 1,22 & 21,71 & 11,394 & 4,399 & 7,539 \\
\hline 9 & 38,98 & 0,010 & 0,039 & 39,03 & 1,21 & 21,77 & 11,782 & 3,356 & 7,273 \\
\hline 11 & 33,81 & 0,011 & 0,088 & 33,91 & 1,08 & 22,04 & 25,115 & 3,231 & 6,090 \\
\hline 13 & 28,23 & 0,006 & 0,081 & 28,32 & 77,45 & 19,96 & 9,310 & 2,948 & 5,443 \\
\hline 14 & 6,75 & 0,028 & 0,361 & 7,14 & 0,08 & 22,25 & 4,698 & 1,998 & 4,196 \\
\hline 16 & 6,71 & 0,053 & 0,057 & 6,82 & 0,07 & 21,63 & 4,157 & 1,916 & 3,801 \\
\hline 19 & 3,81 & 0,261 & 0,108 & 4,17 & 0,06 & 25,78 & 3,311 & 1,845 & 3,074 \\
\hline 20 & 4,40 & 0,010 & 0,006 & 4,42 & 0,05 & 32,67 & 3,674 & 2,107 & 3,010 \\
\hline 23 & 8,26 & 0,005 & 0,012 & 8,27 & 0,08 & 21,64 & 6,616 & 2,352 & 4,613 \\
\hline 26 & 6,78 & 0,276 & 1,370 & 8,43 & 0,34 & 20,26 & 7,070 & 2,356 & 4,676 \\
\hline 28 & 6,77 & 0,220 & 1,165 & 8,16 & 0,36 & 20,03 & 6,797 & 2,411 & 5,006 \\
\hline
\end{tabular}

Tabela 11 - Concentração dos macronutrientes na água, referente à época das águas (verão). Reservatório de Barra Bonita-SP, 2005

\begin{tabular}{|c|c|c|c|c|c|c|c|c|c|}
\hline \multirow{2}{*}{ Ponto } & \multicolumn{10}{|c|}{ Concentração $\left(\mathrm{mg} \mathrm{L}^{-1}\right)$} \\
\cline { 2 - 11 } & $\mathrm{NO}_{3}{ }^{-}$ & $\mathrm{NO}_{2}{ }^{-}$ & $\mathrm{NH}_{4}{ }^{+}$ & $\mathrm{N}$ total & $\mathrm{PO}_{4}{ }^{-}$ & $\mathrm{SO}_{4}{ }^{2-}$ & $\mathrm{Ca}^{2+}$ & $\mathrm{Mg}^{2+}$ & $\mathrm{K}^{+}$ \\
\hline 3 & 44,04 & 0,044 & 0,207 & 44,29 & 2,10 & 26,63 & 15,67 & 8,15 & 3,61 \\
\hline 4 & 41,46 & 0,041 & 4,821 & 46,32 & 2,28 & 32,20 & 14,61 & 8,05 & 3,57 \\
\hline 6 & 22,39 & 0,022 & 1,227 & 23,64 & 2,04 & 24,66 & 14,48 & 7,87 & 3,25 \\
\hline 9 & 25,15 & 0,025 & 0,925 & 26,10 & 1,44 & 21,58 & 14,66 & 7,75 & 3,22 \\
\hline 11 & 24,62 & 0,025 & 1,162 & 25,81 & 0,52 & 25,28 & 14,01 & 8,07 & 3,55 \\
\hline 13 & 22,04 & 0,022 & 0,777 & 22,84 & 0,87 & 20,96 & 13,45 & 8,12 & 3,29 \\
\hline 14 & 4,29 & 0,004 & 0,828 & 5,12 & 0,08 & 22,18 & 8,00 & 6,10 & 1,83 \\
\hline 16 & 3,48 & 0,003 & 0,501 & 3,98 & 0,06 & 22,86 & 8,28 & 6,14 & 1,79 \\
\hline 19 & 3,17 & 0,003 & 0,777 & 3,95 & 0,28 & 23,62 & 6,46 & 5,30 & 1,50 \\
\hline 20 & 3,75 & 0,004 & 0,999 & 4,75 & 0,30 & 26,37 & 8,12 & 6,23 & 1,79 \\
\hline 23 & 13,49 & 0,013 & 1,410 & 14,92 & 0,67 & 22,65 & 8,95 & 6,54 & 1,97 \\
\hline 26 & 12,06 & 0,012 & 0,653 & 12,73 & 0,10 & 22,01 & 10,17 & 6,95 & 2,15 \\
\hline 28 & 9,44 & 0,009 & 1,348 & 10,79 & 0,18 & 19,26 & 9,26 & 6,56 & 1,89 \\
\hline
\end{tabular}


Para o fosfato, verificou-se na estação seca ampla variação na concentração desse composto $\left(0,97\right.$ a $\left.77,45 \mathrm{mg} \mathrm{L}^{-1}\right)$ entre os pontos do rio Tietê e baixos valores para os pontos amostrados no rio Piracicaba $(0,05$ a $\left.0,34 \mathrm{mg} \mathrm{L}^{-1}\right)$. Entretanto, na estação das águas referente aos pontos localizados no rio Tietê, observou-se redução progressiva na concentração de $\mathrm{PO}_{4}{ }^{3-}$ em direção à barragem da UHE, independentemente da época avaliada. Quanto ao rio Piracicaba, nota-se que a amplitude de variação da concentração de fosfato mantém-se constante em relação à época anterior.

Chambers et al. (1994) verificaram que, independentemente das distâncias do efluente estudadas, a presença de altas densidades de plantas aquáticas (valor estimado de $200 \mathrm{~g} \mathrm{~m}^{2}$ ) ocasionou aumento na concentração de fósforo total (30 para $\left.118 \mu \mathrm{g} \mathrm{L}^{-1}\right)$ e nitrogênio total dissolvido (323 para $553 \mu \mathrm{g} \mathrm{L}^{-1}$ ). No presente estudo, observou-se que a maioria das densidades de plantas foi considerada alta $\left(>350 \mathrm{~g} \mathrm{~m}^{-2}\right)$, sendo estimados valores de $901 \mathrm{~g} \mathrm{~m}^{-2}$ no verão, porém a concentração de $\mathrm{N}$ total não foi maior nessas áreas com maior densidade. Já para o fosfato, verificou-se alta concentração no ponto 13, onde foi encontrada a maior área de infestação (2 ha) por $B$. subquadripara registrada no reservatório na estação das águas.

A concentração de $\mathrm{SO}_{4}{ }^{2-}$ não apresentou variações extremas entre épocas e rios avaliados, sendo considerada relativamente constante em relação aos locais e ao tempo, com amplitude de 19,3 a 32,7 $\mathrm{mg} \mathrm{L}^{-1}$. Esses valores são considerados baixos em relação às concentrações máximas toleráveis $\left(250 \mathrm{mg} \mathrm{L}^{-1}\right.$ de $\mathrm{SO}_{4}{ }^{2-}$ ) para água doce classes 1 e 2 (Resolução Conama n ${ }^{\circ} 357$ de 2005). Onaindia et al. (1996) ressaltaram que altos valores de pH estão associados à redução da disponibilidade de fosfato, sulfato, ferro e manganês. Provavelmente, a faixa de $\mathrm{pH}$ alcalino encontrada nos rios analisados, independentemente da época, possa ter influenciado nos teores de sulfato na água. No entanto, algumas espécies são correlacionadas com a concentração de $\mathrm{SO}_{4}{ }^{2-}$, a exemplo de Lemna minor, que coloniza ambientes que apresentam concentrações de $253 \mathrm{mg} \mathrm{L}^{-1}$ (Onaindia et al., 1996).
Quanto às concentrações de $\mathrm{Ca}^{2+}, \mathrm{Mg}^{2+} \mathrm{e}$ $\mathrm{K}^{+}$, independentemente da época avaliada, verificaram-se maiores valores nos pontos localizados no rio Tietê. Contudo, os maiores valores de cálcio e magnésio foram registrados na estação das águas e, para o potássio, na estação seca. A dureza da água refere-se à quantidade de íons de cálcio e magnésio nela presente; no entanto, em alguns casos os ions ferro e manganês também influenciam nessa propriedade As plantas aquáticas, de acordo com a espécie, variam em respostas quanto à dureza da água, como $E$. densa (64 - $144 \mathrm{mg} \mathrm{L}^{-1}$ $\mathrm{CaCO}_{3}$ ) e Cabomba aquatica (16 - $64 \mathrm{mg} \mathrm{L}^{-1}$ $\mathrm{CaCO}_{3}$ ). Ressalta-se que o aumento na dureza da água contribui para a salinidade, devido ao aumento da concentração de íons de cálcio e magnésio.

Contudo, observou-se no presente estudo que $B$. subquadripara apresentou elevado potencial na colonização de áreas, com diferentes concentrações de cálcio tanto no solo quanto na água (no inverno, de 3,3 a $25,1 \mathrm{mg} \mathrm{L}^{-1}$, e no verão, de 8,0 a $15,7 \mathrm{mg} \mathrm{L}^{-1}$ ), sendo registradas produções de massa seca de até 11 toneladas em uma área infestada de dois hectares.

O monitoramento dos fatores abióticos analisados no habitat de $B$. subquadripara permitiu obter informações importantes para estudos futuros que possuem enfoque na predição da ocorrência da espécie em função das condições ambientais favoráveis ao crescimento das plantas. Outro aspecto a ser destacado refere-se ao estado nutricional das plantas, que revela as condições tróficas do ambiente aquático, bem como a interação dessa espécie com o ambiente, resultando em alterações morfofisiológicas, dependendo dos recursos disponiveis.

Assim, observa-se que estudos relacionados à caracterização do habitat de espécies potencialmente infestantes são escassos no Brasil, o que dificultou a comparação dos resultados ora obtidos com os da literatura citada. Ressalta-se também a importância de pesquisas que visam caracterizar o ambiente de ocorrência de espécies aquáticas no Brasil, as quais são necessárias para subsidiar programas de manejo de plantas daninhas aquáticas de forma eficiente em reservatórios de hidrelétricas. 


\section{LITERATURA CITADA}

ALÁEZ, M. F.; ALÁEZ, C. F.; BECARES, E. Nutrient content in macrophytes in spanish shallow lakes. Hidrobiologia, v. 408, n. 409, p. 317-326, 1999.

BARKO, J. W.; ADAMS, M. S.; CLESCERI, N. L. Environmental factors and their consideration in the management of submersed aquatic vegetation: A review. J. Aquatic Plant Manag., v. 24, n. 1, p. 1-10, 1986.

BARKO, J. W.; SMART, R. M. Sediment related mechanisms of growth limitation in submersed macrophytes. Ecology, v. 67, n. 5, p. 1328-1340, 1986.

BARKO, J. W.; SMART, R. M. Effects of organic matter additions to sediment on the growth of aquatic plants.

J. Ecol., v. 71, n. 1, p. 161-175, 1983.

BOON, P. J. The relevance of ecology to the statutory protection of British rivers. In: HARPER, D. M.; FERGUSON, A. J. D. (Eds). The ecological basis for river management. Chichester: John Wiley \& Sons, 1995. p. $239-250$.

CAVENAGHI, A. L. et al. Caracterização da qualidade de água e sedimento relacionados com a ocorrência de plantas aquáticas em cinco reservatórios da bacia do rio Tietê Planta Daninha, v. 21, p. 43-52, 2003. (Edição Especial)

CARVALHO, F. T. et al. Eficácia do carfentrazone-ethyl no controle de plantas aquáticas latifoliadas em caixas-d'água. Planta Daninha, v. 23, n. 2, p. 305-310, 2005.

CHAMBERS, P. A. et al. Nutrient dynamics in riverbeds: the impact of sewage effluent and aquatic macrophytes.

Water Res., v. 28, n. 2, p. 453-464, 1994.

CONSELHO NACIONAL DE MEIO AMBIENTE CONAMA. Resolução CONAMA n 357. 2005. Disponível em: <http:\|www.mma.gov.br> Acesso em: 15 jul. de 2010

GIUSTI, E.; LIBELLI, S. M. Modelling the interactions between nutrients and the submersed vegetation in the Orbetello Lagoon. Ecol. Model., v. 184, p. 141-161, 2005.

JACKSON, L. J.; KALFF, J. Patterns in metal content of submerged aquatic macrophytes: the role of plant growth form. Freshwater Biol., v. 29, n. 3, p. 351-359, 1993.

JACKSON, L. J.; KALFF, J.; RAMUSSEN, J. B. Sediment $\mathrm{pH}$ and redox potential affect the bioavailability of $\mathrm{Al}, \mathrm{Cu}, \mathrm{Fe}$, $\mathrm{Mn}$, and $\mathrm{Zn}$ to rooted aquatic macrophytes. Can. J. Fish. Aquatic Sci., v. 50, n. 1, p. 143-148, 1993.
KISSMANN, K. G. Plantas infestantes e nocivas. 2.ed. São Paulo: BASF, 1997. Tomo I. 825 p.

MARTINS, D. et al. Ocorrência de plantas aquáticas nos reservatórios da Light-RJ. Planta Daninha, v. 21, p. 105-108, 2003. (Edição Especial)

MARTINS, D. et al. Caracterização da comunidade de plantas aquáticas de dezoito reservatórios pertencentes a cinco bacias hidrográficas do Estado de São Paulo. Planta Daninha, v. 26, n. 1, p. 17-32, 2008

MARTINS, D. et al. Levantamento da infestação de plantas aquáticas em Porto Primavera antes do enchimento final do reservatório. Planta Daninha, v. 27, p. 879-886, 2009. (Edição Especial)

MONTEIRO, C. A. F. A dinâmica climática e as chuvas do Estado de São Paulo: estudo em forma de atlas. São Paulo: IGEOG/USP, 1973.

NOVO, E. M.; LEITE, F. O Sistema de Informações Geográficas do Reservatório da UHE Barra Bonita. In: SIMPÓSIO BRASILEIRO DE SENSORIAMENTO REMOTO, 8., 1996, Salvador. Anais... Salvador: INPE, 1996 p. $227-232$.

ONAINDIA, M.; BIKUNA, B. G; BENITO, I. Aquatic plants in relation to environmental factors in Northern Spain. J. Environ. Manag., v. 47, n. 2, p. 123-137, 1996.

POTT, A.; POTT, V. J. Features and conservation of the Brazilian Pantanal wetland. Wetlands Ecol. Manag., v. 12, n. 6, p. 547-552, 2004.

$\mathrm{PRADO}, \mathrm{R}$. B. Geotecnologias aplicadas à análise espaçotemporal do uso e cobertura da terra e qualidade da água do reservatório de Barra Bonita-SP, como suporte à gestão de recursos hídricos. 2004. 158 f. Tese (Doutorado em Ciências da Engenharia Ambiental) - Escola de Engenharia de São Carlos/USP, São Carlos, 2004

RAIJ, B.van. Fertilidade do solo e adubação. Piracicaba: Agronômica Ceres/POTAFÓS, 1997. 343 p.

TOETZ, D. W. Uptake and translocation of ammonia by freshwater hydrophytes. Ecology, v. 55, n. 1, p. 199-201, 1974.

WERNER, J. C. Adubação de pastagens. Nova Odessa: Instituto de Zootecnia, 1986. 49 p. (Boletim Técnico, 18) 